\title{
Cardiac responses to signal and nonsignal tasks in 9-year-olds*
}

\author{
RAFAEL KLORMAN \\ University of Rochester, Rochester, N.Y. 14627 \\ and \\ PETER J. I.ANG \\ University of Wisconsin, Madison, Wis. 53706
}

This study investigated the cardiac waveform of 9-year-olds' responses to highand low-intensity nonsignal pure tones and to a simple reaction time (RT) task. Responses to the nonsignal tones were not affected by stimulus intensity and consisted of slight initial deceleration followed by pronounced acceleration. Responses to the RT task also consisted of an initial deceleration and larger acceleration plus a prominent deceleration, peaking at the onset of the imperative stimulus. These waveforms generally resembled those found in adults.

Some recent psychophysiological work on adults (e.g., Graham \& Clifton, 1966) has dealt with heart rate changes in nonsignal situations as a function of stimulus intensity. Deceleration has commonly been found in response to novel stimuli of moderate intensity and acceleration to higher intensities. In signal conditions like simple reaction time (RT) tasks, deceleration time-locked to the imperative stimulus has been observed (Coquery \& Lacey, 1968). The present study investigated changes in 9-year-olds' cardiac rate in nonsignal tasks varying in stimulus intensity and in a simple RT task.

\section{METHOD}

Twelve boys in the age range of 8.5 to 10.5 years were selected randomly from the Central Madison, Wisconsin, Y.M.C.A. membership list. Two sessions were held at the same time of day for each $S$ and were spaced 7 to 10 days apart. Both sessions were conducted in a partially soundproofed and electrically shielded room. S was seated in a reclining chair and told that Es wanted to learn about the performance of boys his age on some tests he would be asked to take. After attachment of electrodes, the room was darkened and a $10-\mathrm{min}$ adaptation period elapsed. Before each experimental procedure was initiated, $E$ returned to S's room to describe the next task and then departed. One minute later, the appropriate

*This study was supported by NIMH Predoctoral Fellowship 2-F01-MH36669 to the first author and NIMH Grant MH10993 to the second author. We acknowledge the able assistance of Bruce Cuthbert in transporting and testing $\mathrm{Ss}$; Michael Falconer in computer programming; Frances $K$. Graham in providing a computer program for statistical analyses; and Kent Hayes in designing the apparatus. A grant from the University of Wisconsin Graduate School provided free computer time, and the Madison Academic Computer Center furnished computing facilities and consulting. experimental procedure was initiated; 5 min breaks were interpolated between treatments.

The format of the two sessions was identical. The primary purpose of Session 1 was to induce adaptation to the experimental setting; therefore, each treatment was limited to only half the number of trials presented in Session 2, plus one practice trial.

One signal and two nonsignal conditions were administered. In the two nonsignal manipulations, there were eight presentations of a 2 -sec $800-\mathrm{Hz}$ tone at 60 and $80 \mathrm{~dB}$, respectively, superimposed on a $45-\mathrm{dB}$ background (General Radio Sound Level Meter, Scale C). The signal conditions involved eight trials of a simple RT task. Warning and imperative stimuli were two $60 \mathrm{~dB}$ tones, characterized by the same parameters as above and separated by a 6-sec interstimulus interval (ISI, offset to onset). $S$ was requested to remain still and relaxed throughout and to pay attention to the auditory stimuli. Two Ss were assigned to each of the six possible sequences of treatments. In both sessions, the same sequence was followed for a given $S$.

Intertrial intervals (ITIs) were controlled manually by $\mathrm{F}$ from a prepared list of random ITIs of 40-90 sec. The tones were generated by a Hewlett-Packard oscillator and were shaped by a controlled ramp electronic switch with exponential 10-msec rise- and fall-time. A Scott amplifier fed the signal to a Jensen speaker positioned on a stand $17 \mathrm{in}$. above the ground and. 38 in. in front of $\mathrm{S}$. ISIs during the RT condition were controlled by a solid state logic, and latencies were retrieved from a Berkeley frequency meter.

The electrocardiogram (EKG) was detected by two Beckman electrodes aligned vertically along the sternum; an earclip served as ground. The EKG, recorded by a Grass Model 5 polygraph, and a pulse marking stimulus occurrence were output through a Vetter FM converter into a Concertone AM tape recorder.

These data were played back trial by trial at real time into a Digital LINC 8 computer with extended memory and a millisecond clock. R-R intervals were measured by the computer to the nearest millisecond and subsequently converted into average rate/sec, each beat being weighted by the proportion of a second that it took up. The average of 2 sec prestimulus was computed as an estimate of baseline.

\section{RESULTS}

Figure 1 presents the average

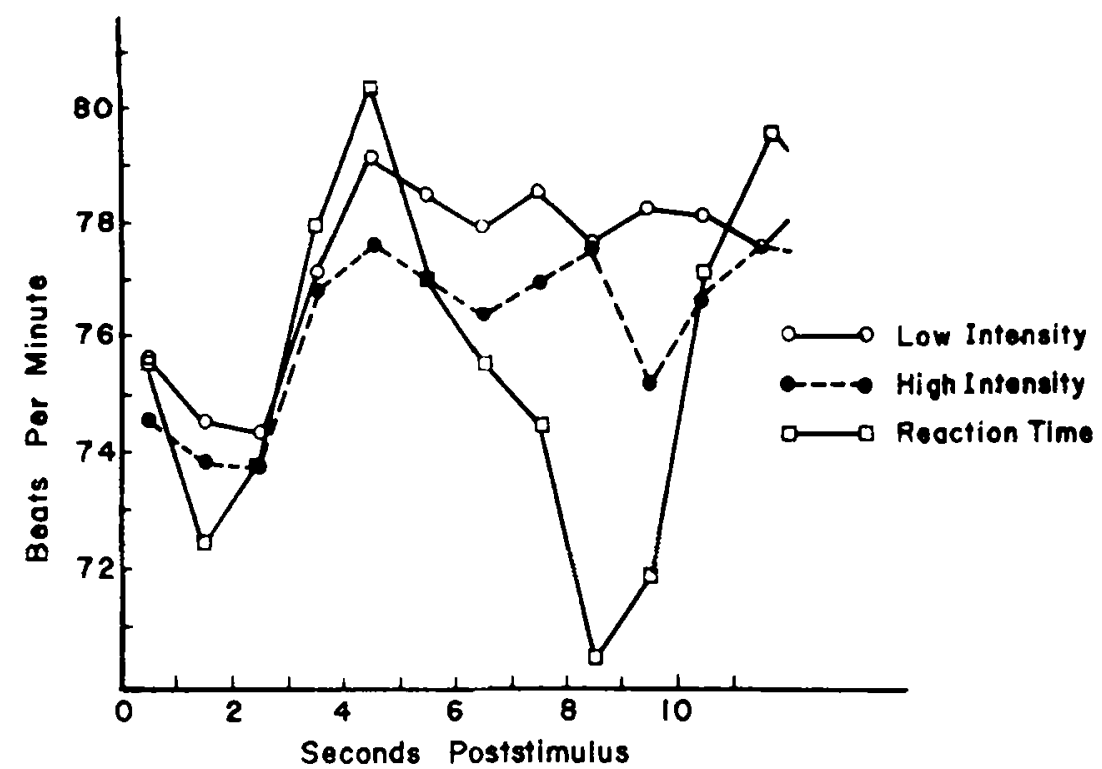

Fig. 1. Cardiac wa veform for each experimental condition.

Psychon. Sci., 1972, Vol. 28 (5) 
cardiac curves for each condition. All curves showed a 1 - or 2 -sec initial deceleration, followed by a larger acceleration above baseline, peaking at Second 4. In the nonsignal curves, there ensued irregular deceleration without a complete return to baseline. In contrast, the RT curve exhibited a pronounced deceleration below baseline that peaked at Second 8 (onset of the imperative stimulus).

A variance and polynomial analysis on baseline and poststimulus Seconds 1-8 indicated that the curves for the three conditions differed significantly in waveform (Conditions by Seconds linear $F=9.66$, and Conditions by Seconds quadratic $\mathrm{F}=$ $14.56 ; \mathrm{df}=2 / 12, \mathrm{p}<.005)$. Therefore, separate analyses were undertaken for signal and nonsignal conditions. Nonsignal conditions yielded curves essentially unaffected by intensity $(F=3.08$, $d f=1 / 6$, n.s. $)$, trials $(F<1$, df $=7 / 42$, n.s. $)$, or sequences $(F=1.43, \mathrm{df}=5 / 6$, n.s. $)$. These waveforms were fitted by linear $(\mathrm{F}=22.88, \mathrm{df}=1 / 6, \mathrm{p}<.005)$, quadratic $(\mathrm{F}=3.85, \mathrm{df}=1 / 6$, $\mathrm{p}<.10)$, and quartic $(\mathrm{F}=8.04$, $\mathbf{d f}=$ $1 / 6, p<.05$ ) trends. The linear and quadratic trends, accounting for $58 \%$ and $8 \%$ of the seconds variance, respectively, seem to reflect the small initial deceleration and the more prominent subsequent acceleration of both curves.

The overall RT curve was characterized by significant quadratic $(F=18.87, \mathbf{d f}=1 / 10, p<.005)$, cubic $(F=6.30$, df $=1 / 10, p<.05)$, and quartic $(F=11.24, \mathrm{df}=1 / 10, p<.01)$ trends of seconds; the polynomials accounted for $54 \%, 14 \%$, and $17 \%$, respectively, of the variation. The quadratic and cubic trends may be interpreted as reflecting the slight initial deceleration following the warning tone, the subsequent large acceleration, and prominent final deceleration time-locked to onset of imperative stimulus.

Changes in the RT curve as a function of between- and within-S latency were examined; no differences emerged from statistical analysis of median splits of fast vs slow Ss or fast vs slow trials within the same $\mathrm{S}$.

In order to evaluate treatment differences further, four response components identified in adults' cardiac responses (Connor \& Lang, 1969) were computer-scored on each $S$ 's average cardiac curve. Deceleration 1 was defined as the difference between baseline rate and the second with the lowest rate in Poststimulus Seconds 1-3. Acceleration 1 was scored as the difference between the latter parameter and the subsequent second, with the highest rate through Poststimulus Second 5. The difference between the latter point and the second with the lowest rate through poststimulus Second 9 defined Deceleration 2. Finally, the Lang-Hnatiow peak-to-valley measure was scored as the difference between the second with the highest rate within Poststimulus Seconds $1-5^{-}$and the subsequent second with the lowest rate through Poststimulus Second 9. All responses were reflected, and negative differences were scored zero.

Variance analyses disclosed treatment differences only for Deceleration $2(F=12.99, d f=2 / 12$, $p<.005)$ and peak-to-valley $(\mathrm{F}=$ $14.42, \mathrm{df}=2 / 12, \mathrm{p}<.005)$. Fisher's l.s.d. technique indicated that both measures of secondary deceleration were larger in the RT than in either nonsignal condition ( $p<.01$ or less); no differences emerged between nonsignal treatments.

DISCUSSION
The waveforms obtained to nonsignal and signal stimuli replicated those detected in adults (Connor \& Lang, 1969). However, the finding of no differences between intensity levels of nonsignal stimuli departed from results obtained from adults. Perhaps this finding reflects a reliable developmental trend. Alternatively, this result might be due to the relatively moderate intensity differential ( $30 \mathrm{~dB}$ ) or the possible adaptation of initially different waveforms in the second recording session, during which the data were collected.

The RT waveform resembles comparable curves from adults (e.g., Coquery \& Lacey, 1966) and children (Sroufe, 1971; Obrist, Howard, Sutterer, Sterling Hennis, \& Murrell, 1967). However, in contrast to Sroufe's (1971) report, no relationship was obtained between reaction time and heart rate within or across Ss.

\section{REFERENCES}

CONNOR, W. H., \& LANG, P. J. Cortical slow wave and cardiac rate responses in stimulus orientation and reaction time conditions. Journal of Experimental Psy chology, 1969,82, 310-320.

COQUERY, J. M., \& LACEY, J. I. The effect of foreperiod duration on the components of the cardiac response during the foreperiod of a reaction-time experiment. Paper delivered at a meeting of the Society for Psychophysiological Research, Denver, 1966.

GRAHAM, F. K., \& CLIFTON, R, K llcart-rate change as a component of the orienting response. Psychological Bulletin, 1966, 65, 305-320.

OBRIST, P. A., HOWARD, J. L. SUTTERER, J. R., STERLING HENNIS, H., \& MURRELL, D. J. Cardiac-somatic changes during a simple reaction time task: A developmental study. Paper delivered at a meeting of the Society for Psychophysiological Research, Monterey. 1969 .

SROUFE, L. A. Age changes in cardiac deceleration within a fixed foreperiod reaction time task: An index of attention. Developmentál Psychology, 1971, 5 . 338-343. 